\title{
A HISTOLOGICAL AND CHEMICAL STUDY OF THREE CASES OF DIFFUSE CEREBRAL SCLEROSIS
}

\author{
BY \\ W. BLACKWOOD and J. N. CUMINGS \\ From the National Hospital and the Institute of Neurology, Queen Square, London
}

In 1950 Greenfield proposed a classification of the various forms of diffuse demyelinating sclerosis on the basis of pathogenesis and tissue reaction. His classification may be restated, but with minor modification as follows :-

(1) Cases in which, histologically, the appearances are similar to those seen in disseminated sclerosis. Included in this group are cases with concentric demyelination of the Balo type and cases with perivascular islands of residual myelin as in Pelizaeus-Merzbacher's disease.

(2) Cases in which the apparent products of myelin katabolism are predominantly metachromatic lipids. Included in this group are those in which there is associated degeneration of the interfascicular oligodendroglia (Greenfield, 1933 ; Brain and Greenfield, 1950) and those in which the oligodendroglia appear normal in histological perparations (Norman, 1947).

(3) Cases in which, histologically, the myelin is replaced partly by neutral fat and partly by some chemical substance which excites an "epithelioid" cell or " globoid" body reaction. Such a condition was first described by Krabbe (1916).

(4) Cases which. in the present state of our knowledge, do not fit into the above groups.

If will be noted that in the above classification no emphasis is placed upon the familial or nonfamilial nature of the disorders or upon the age of the patients.

This paper records the results of histological and chemical examinations in three cases diagnosed on macroscopic examination as diffuse cerebral sclerosis. These findings are discussed in so far as they are related to pathogenesis and to the place to be occupied by each in the above classification.

The cases were: A, a case with "spongy degeneration" of the cerebral white matter (Canavan); B, a case with perivascular islands of residual myelin (Pelizaeus-Merzbacher); C, a case with numerous " globoid" bodies or "epithelioid" cells in the white matter (Krabbe).
Histological Methods

Various portions from the brains (and the spinal cord in case A), which had been fixed in formol saline were embedded and stained by the following methods :X Celloidin Sections.-Anderson's iron haematoxylin and van Gieson, Mallory's phosphotungstic acid haematoxylin ; Loyez' haematoxylin and Kultschitsky-Pal for myelin, Gros-Bielschowsky for axis cylinders, Nissl (thionin), Mayer's mucicarmine and haematoxylin, Hotchkiss-Schiff periodic acid-fuchsin (P.A.S.), and Congo red.

Frozen Sections.-Sharlach R and Mayer's haemalum, Sudan black B, toluidine blue mounted in " microil " for metachromatic material, Hortega for microglia, P.A.S. and Congo red.

\section{Chemical Methods}

Various portions of the brains were examined within two weeks of the post-mortem examination from each of the three cases. Water content, total phospholipin, monoamino-phospholipin, sphingomyelin, lecithin, kephain, rree and total cholesterol, cerebroside and neuraminic acid were estimated by the techniques used in a simiar chemical investigation in disseminated sclerosis and amaurotic family idiocy (Cumings, 1953).

\section{Case A (Spongy Degeneration)}

Clinical History.-C. M. was a boy (N.H. No. 28860) whose family history contained nothing significant. One younger brother, aged 3 months, was healthy. There was no maternal illness during pregnancy. Birth was normal and the circumference of the head was normal. At 2 months of age he had convulsions and was admitted to Edgware General Hospital under Dr. M. D. Baber. Here the lumbar cerebrospinal fluid (C.S.F.) was examined and found to be normal. A lumbar air encephalogram revealed ventricles which were normal in size and shape. At 5 months the circumference of the head was $1.3 \mathrm{in}$. $(33 \mathrm{~mm}$.) larger than normal. He continued to have epileptic attacks. At 6 months teething started. At this time he was admitted to The Hospital for Sick Children, Great Ormond Street, under Dr. R. Lightwood, where it was noted that the pupils did not react to light and the optic discs appeared atrophic. The skull gradually enlarged abnormally and 
at 17 months was 3.25 in. (82 mm.) greater in circumference than normal. At 22 months he was admitted to the National Hospital, Queen Square, under the care of Sir Charles Symonds. He was a lethargic child. Awareness and consciousness fluctuated considerably. The skull circumference was 3.6 in. $(91 \mathrm{~mm}$.) greater than normal. The child appeared to be blind and there was pallor of both optic discs. There was bilateral ptosis, more marked on the left side, and there was failure of full inward and downward movement of the left eye. The pupils reacted sluggishly to light. There was a left-sided facial weakness. He gave a generalized startle reaction to noise in either ear. Muscle tone was greatly increased in all limbs, but power could not be assessed. The reflexes were present and not increased, but both plantar responses were extensor. He responded to and accurately located pinprick on either side of the body. No definite abnormality was found in the E.E.G. (Dr. W. A. Cobb). X-ray examination (Dr. S. Moor) showed that the skull vault was enlarged and thin for the age of the patient. There was a disproportion between the size of the vault and the facial bones. The posterior fossa did not appear to have increased proportionately in size with the rest of the skull vault. Both anterior and middle fossae were shallow and the pituitary fossa also appeared to be somewhat flat. There was no suture diastasis. He developed bronchitis and bronchopneumonia and died at the age of 23 months.

\section{Post-mortem Findings (PM.13/51) in Case A}

Necropsy was performed three hours after death. The body was that of a well developed, well nourished child with an enlarged head, the enlargement being assymetrical, temporal on the right side, parietal on the left. The serous sacs were healthy. The lungs showed congestion and oedema. The cardiovascular (heart 70 g.), endocrine, and lymphvascular systems (spleen 20 g.) appeared healthy. The alimentary system was healthy apart from diffuse pallor of the liver $(380 \mathrm{~g}$.). The urogenital system appeared healthy (kidneys, left $50 \mathrm{~g}$., right 55 g.).

Central Nervous System.-The cavity of the skull was asymmetrical but the capacity on either side of the falx cerebri appeared about equal. The bones of the vault were thin. The fontanelles were closed. The dura, venous sinuses, basal vessels and leptomeninges appeared healthy. The cerebral hemispheres were larger than usual, but the surface was not flattened; indeed on the left side there appeared to be slight gyral atrophy in the region of the central sulcus. The cerebellum appeared normal and the foramen of Magendie was large. The corpus callosum was unduly firm and pinkish grey, The medulla and spinal cord appeared normal. On section (Figs. 1 and 2) the contex and basal ganglia were less clearly demarcated from the white matter than usual. Most of the white matter appeared abnormal. Anteriorly, in the frontal lobes, it was very soft and of a pearly appearance. Passing posteriorly to the occipital poles the white matter became pinkish grey firmer and more clearly demarcated from the somewhat thin but otherwise normal looking cortex. The corpus callosum was thin, especially in its posterior half. The basal ganglia appeared to be of normal size. The caudal portions of the internal capsules were firmer and of a more creamy colour than the rest of the white matter, but in the midbrain, pons, and medulla the peduncles and the pyramidal tracts were slightly shrunken. The pons appeared to be a little smaller than usual on cross section, but the transverse fibres of the pons appeared well myelinated. The cerebellum showed slight general atrophy of the folia in both the vermis and the hemispheres, associated with a greyish pink discoloration of the central white matter in the posterior and inferior portions of the hemispheres. The atrophy of the cerebellar folia appeared to be due to the loss of white matter. All lesions appeared to be bilaterally symmetrical. The ventricles, especially the posterior horns of the lateral ventricles and the fourth ventricle, were enlarged. The cerebral hemispheres together weighed $1,440 \mathrm{~g}$. ; the cerebellum $135 \mathrm{~g}$. ; the brain-stem $20 \mathrm{~g}$. ; total weight of the brain 1,595 g. (normal 1,059 g.). The spinal cord appeared healthy.

Histological Findings.-The central nervous system was the site of a widespread pathological process. The leptomeninges and cortical blood vessels appeared healthy. The cerebral cortical laminar pattern was not disturbed, nor were the nerve cells noticeably diminished in number, or otherwise abnormal (Fig. 3), but between the nerve cells, in the deeper layers of the contex, in layers 4 , 5 , and 6 there were numerous large, rounded spaces, some as large as $100 \mu$ in diameter (D. Fig. 4 and 5). These spaces sometimes appeared empty (A. Fig. 4), sometimes contained granular material radiating out from a nucleus, which was usually small and hyperchromatic (A. Fig. 5). Sometimes a capillary ran through a cystic space (B. Fig. 4). Neither lipid, metachromatic material, or P.A.S.-positive material could be seen in the cystic spaces. Microglia and their processes (in sections impregnated with silver) often stretched out at the periphery of a cyst, or the granular material in the cyst would stain deeply with silver, but it was not certain that the microglia were encompassing these spaces or any material which was or might have been present in them. Sometimes there were cystic spaces around capil- 
laries and all the larger blood vessels showed dilatation of the perivascular spaces (Fig. 4). Almost as striking as the cystic change in the cortex, was the change in the astrocytes of all layers. These cells were increased in number, often in pairs or threes. Their nuclei were often large, up to twice normal size, without any increase in chromatin but with prominence of the nuclear membrane (B. Fig. 5). Around the nucleus in celloidin sections there was often a small round or ovoid space (C. Fig. 4), which was sometimes empty and sometimes contained a finely granular material. The processes of the astrocytes were greatly thickened (Fig. 8). In the frontal cortex glial fibrils could be occasionally seen in these processes; in the parietal, temporal, and occipital cortex fibrils were more frequent.

The white matter in its most superficial part was largely replaced by cystic spaces, similar to those seen in the deeper grey matter, which were separated by tissue in which oligodendroglial and swollen astrocytic nuclei were visible. The rest of the cerebral white matter contained numerous smaller clear spaces separated by similar tissue (Fig. 10). The astrocytic processes were again enlarged (Fig. 9) and in the parietal, temporal, and occipital cortex there was glial fibre formation. In this same tissue ran numerous axons (Fig. 11). The perivascular spaces were not enlarged.

Myelin was found with difficulty in the cortex and white matter. It was not seen in Loyez preparations, but in Sudan black $B$ preparations occasional myelinated fibres and many globules of lipid were seen.

Changes similar to those in the cortex were seen in the putamen, globus pallidus (Fig. 12), and thalamus. The retinae did not show any significant abnormality and the optic nerves were myelinated and were not vacuolated. The optic tracts were myelinated but vacuolated; the optic radiations were not myelinated. The internal capsule was myelinated, the corpus callosum and fornix contained numerous myelinated fibres, and all were vacuolated. The choroid plexus appeared normal, and although the ependyma lining the ventricles was not everywhere intact, there was no special cellular reaction in the regions from which it was absent. In the cerebellum (Fig. 13) there was persistence of the external granular layer of Obersteiner in both vermis and hemispheres. The cystic abnormality was present and was most marked in the Purkinje cell layer. The Purkinje cells, which were not appreciably decreased in number, were displaced into the molecular layer. Cystic replacement was also present in the granule cell layer and the white matter. The layer of Bergmann cell astrocytes was displaced superficially. This layer was broadened and composed of very numerous, loosely packed, large pale nuclei (Fig. 14). Glial fibres could not be demonstrated. The white matter contained numerous axons but very little myelin. The dentate nuclei showed astrocytic hyperplasia and contained small vacuoles but the nerve cells were not destroyed.

In the midbrain the superior cerebellar peduncles were well myelinated (Fig. 15). All other regions contained cysts and showed astrocytic increase in number and nuclear size. In the pons the transverse fibres and the middle cerebellar peduncles were well myelinated, but were again cystic (Fig. 16).

The medulla was well myelinated, but cystic change was present except in the pyramidal tracts. The inferior olivary nuclei, like the other grey nuclei of the brain-stem, appeared healthy apart from cystic change. The spinal cord was cystic and well myelinated apart from the crossed pyramidal tracts, which showed a slight loss of both myelin sheaths and axons. Occasional fat phagocytes were present here in the perivascular spaces. The third and fifth cranial nerves, after they had left the brain-stem and such spinal nerve roots as were visible, all appeared well myelinated and healthy.

The lungs showed congestion and oedema. The liver showed moderate fatty change. The spleen was congested. The thyroid, pancreas, heart, thymus, pituitary, kidney, peripheral nerve, and muscle did not show any significant abnormality.

Chemical Results.-Table 1 gives the results of the analysis of the brain in this case. Normally

TABLE I

LIPID CONTENT OF BRAIN* IN SPONGY TYPE

\begin{tabular}{|c|c|c|c|c|c|c|}
\hline & & & \multicolumn{2}{|c|}{ Cerebral White } & \multirow[b]{2}{*}{$\begin{array}{l}\text { Cerebral } \\
\text { Cortex }\end{array}$} & \multirow[b]{2}{*}{$\begin{array}{c}\text { Basal } \\
\text { Ganglia }\end{array}$} \\
\hline & & & $\begin{array}{c}\text { Appar- } \\
\text { ently } \\
\text { Normal }\end{array}$ & $\begin{array}{l}\text { Demye- } \\
\text { linated }\end{array}$ & & \\
\hline $\begin{array}{l}\text { Total phospholip } \\
\text { Monoamino phos } \\
\text { Sphingomyelin } \\
\text { Lecithin .. } \\
\text { Kephalin . } \\
\text { Total cholesterol } \\
\text { Free cholesterol } \\
\text { Cerebroside. . } \\
\text { Water . . }\end{array}$ & $\begin{array}{l}\text { hol } \\
\ldots \\
\cdots \\
\cdots \\
\cdots \\
\cdots\end{array}$ & $\begin{array}{l}\cdots \\
\cdots \\
\therefore \\
\therefore \\
\therefore \\
\therefore\end{array}$ & $\begin{array}{l}0 \cdot 9 \dagger \\
0 \cdot 8 \\
0 \cdot 1 \\
0 \cdot 3 \\
0 \cdot 5 \\
0 \cdot 55 \\
0 \cdot 44 \\
0 \cdot 49 \\
92 \cdot 2\end{array}$ & $\begin{array}{l}1 \cdot 1 \\
0.9 \\
0.2 \\
0.45 \\
0.45 \\
0.43 \\
0.43 \\
0.57 \\
91.5\end{array}$ & $\begin{array}{l}1.92 \\
1.46 \\
0.46 \\
0.7 \\
0.76 \\
0.87 \\
0.87 \\
0.74 \\
85.6\end{array}$ & $\begin{array}{l}1.93 \\
1.5 \\
0.43 \\
0.8 \\
0.7 \\
0.77 \\
0.55 \\
0.69 \\
87.0\end{array}$ \\
\hline
\end{tabular}

* Brain formalin fixed for two weeks.

+ Results in g./100 g. fresh tissue.

smaller amounts of all lipids are present in the brain of a child as compared with those found in an adult (Brante, 1949). Here, in the white matter, 


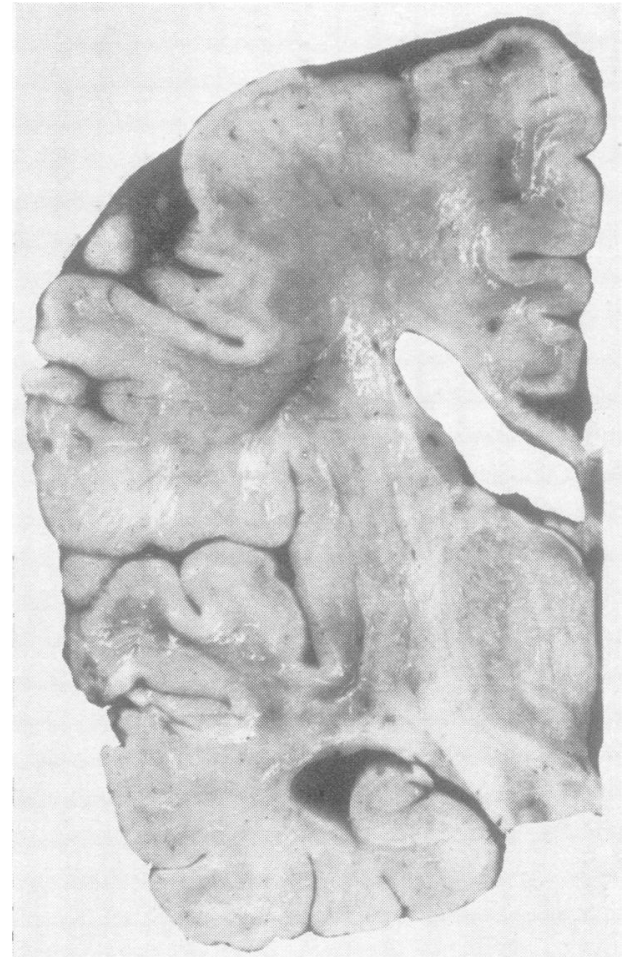

Fig. 1

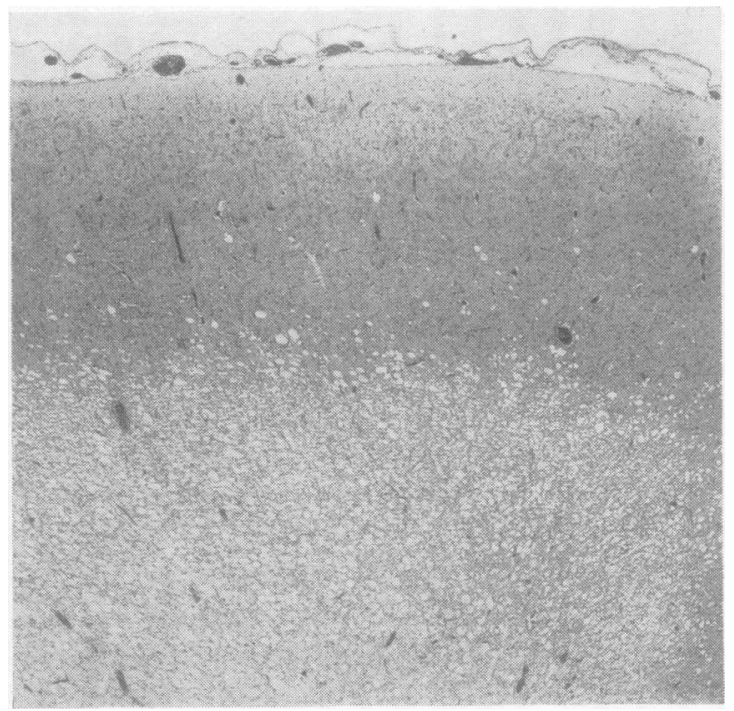

FIG. 3

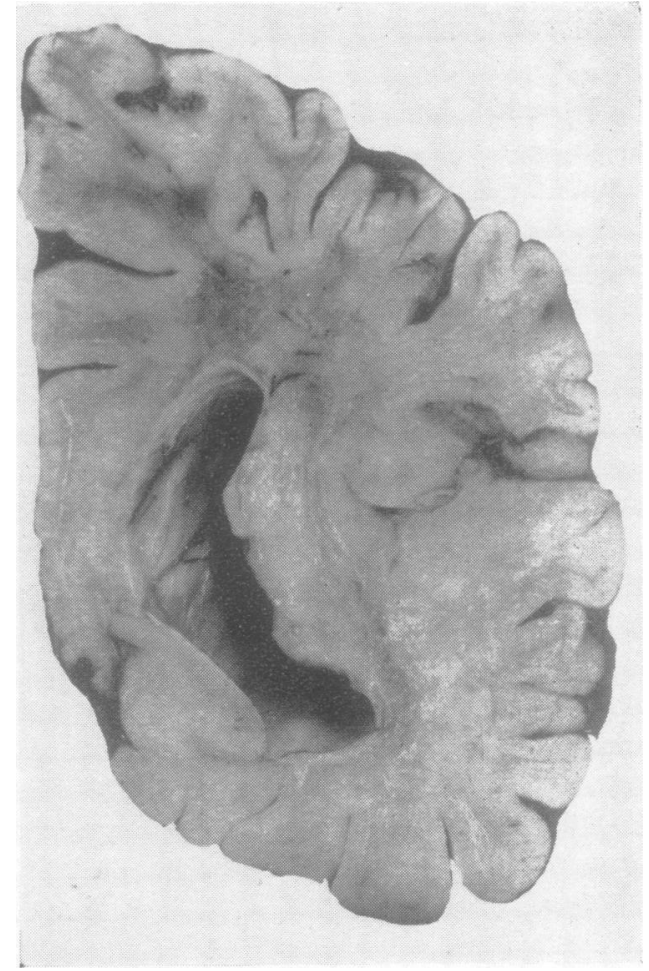

FIG. 2

Fig. 1.-Anterior surface of coronal section at the level of the red nucleus.

Fig. 2.-Anterior surface of coronal section at the level of the vestibule of the lateral ventricle, which is enlarged.

FIG. 3.-Parietal region. Note the spongy change in the deeper layers of the cortex and in the white matter. Celloidin, haematoxylin, van Gieson, $\times 16$.

FIG. 4.-Parietal region. Deeper layers of cortex. Note the large rounded clear spaces (A and B) : across one of them (B) runs a capillary. The astrocytic nuclei (C) are increased in number and size compared to the normal control (Fig. 6) and often are surrounded by a poorly stained halo. The perivascular space (D) is increased in size. Celloidin, haematoxylin van Gieson, $\times 250$.

Fig. 5.-Similar region to Fig. 4. At $\mathrm{A}$ is a space containing granular material radiating from a small hyperchromatic nucleus. At $B$ is an enlarged astrocytic nucleus. Celloidin, haematoxylin, van Gieson, $\times 200$.

Fig. 6.-Control normal cortex for comparison with Figs. 4 and 5. Celloidin, haematoxylin, van Gieson, $\times 200$.

FIG. 7.-Control normal white matter impregnated for astrocytes. Frozen, Cajal's gold sublimate, $\times 375$.

Fig. 8.-Parietal cortex stained as Fig. 7. The astrocytes are increased in number, and their processes are thickened. $\times 375$.

FIG. 9.-Parietal white matter stained as Fig. 7. The astrocytes are enlarged compared to the normal (Fig. 7) and their processes often surround the cystic spaces. $\times 375$.

FIGs. 1-16.-Spongy degeneration as shown in Case A. 


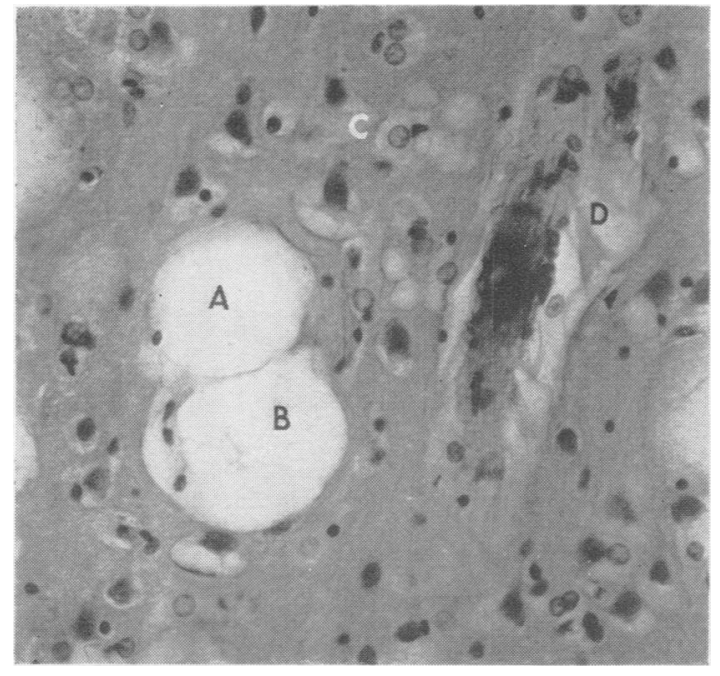

FIG. 4

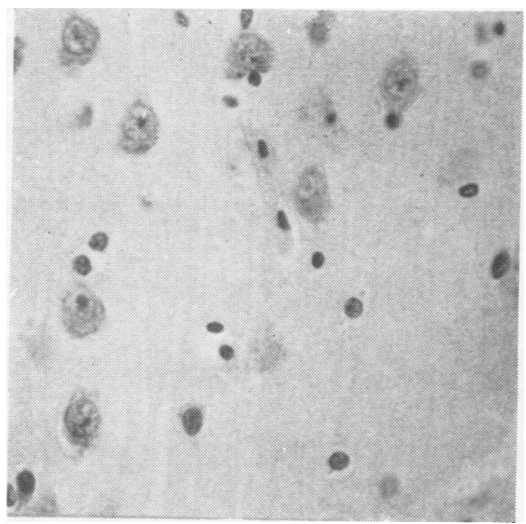

FIG. 6

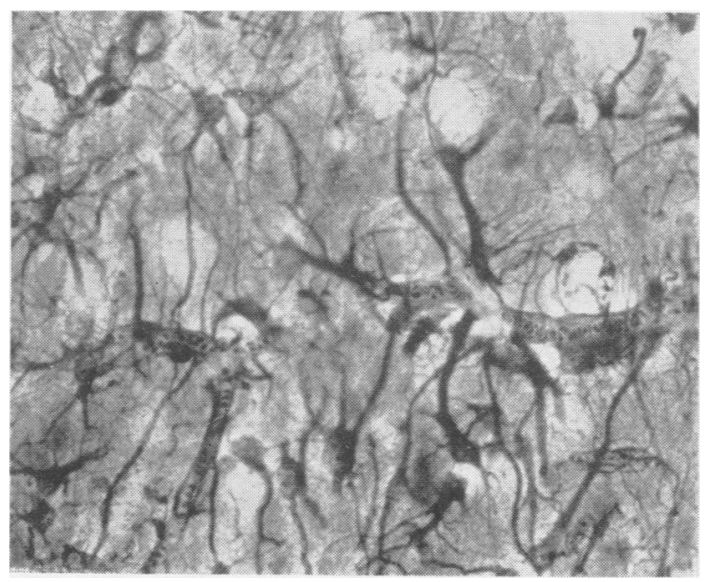

FIG. 8

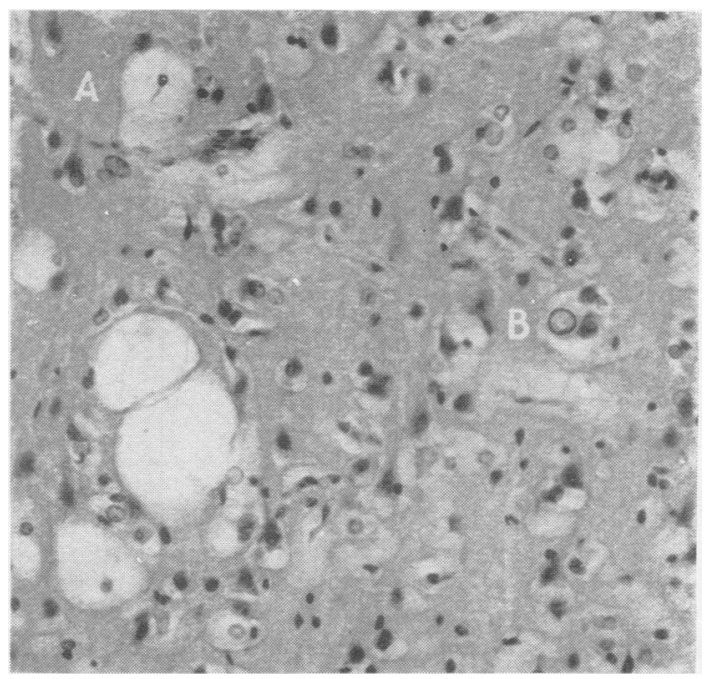

FIG. 5

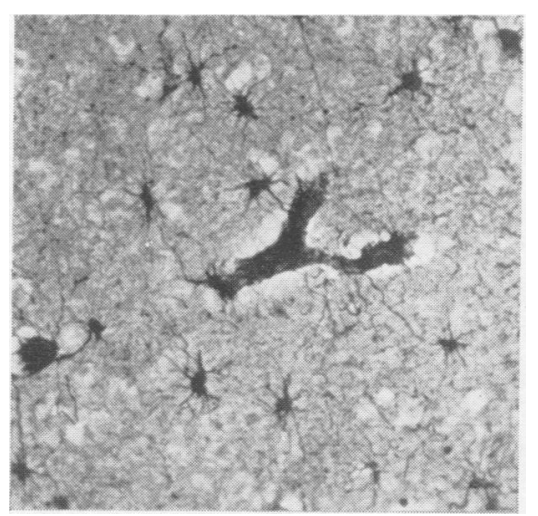

FIG. 7

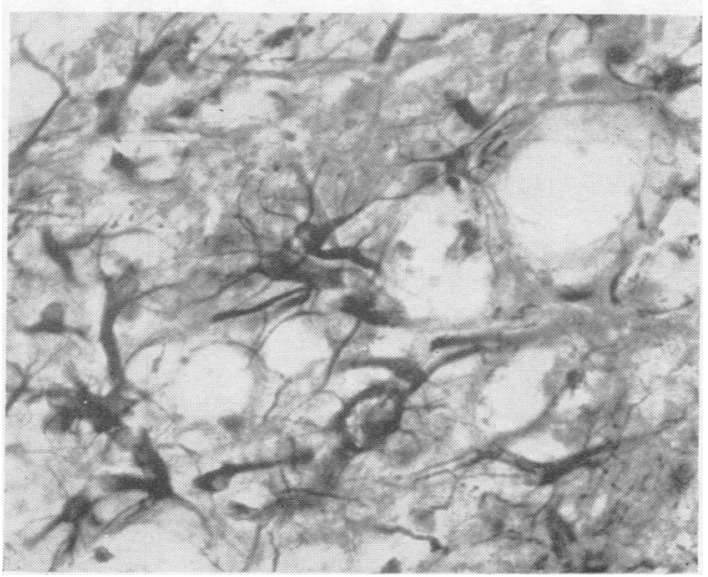

FIG. 9 


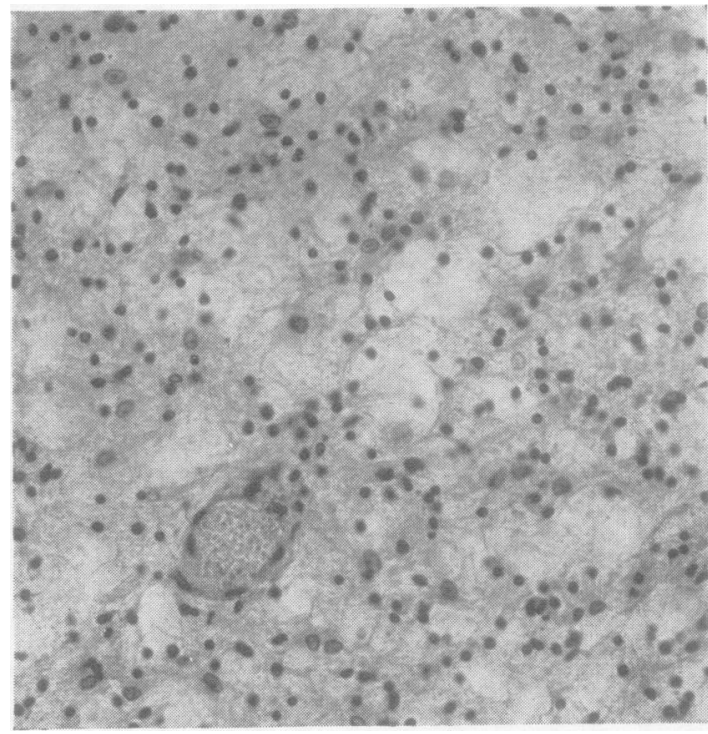

FIG. 10.-Parietal deep white matter, showing the smaller cystic spaces separated by tissue in which oligodendroglial and swollen astrocytic nuclei are present. Celloidin, haematoxylin, van Gieson, $\times 215$.

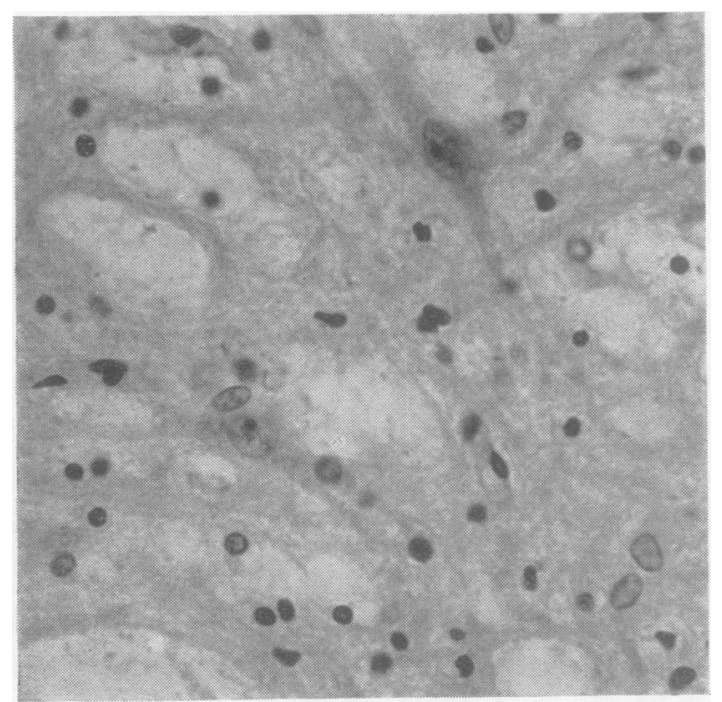

Fig. 12.-Globus pallidus showing nerve cells, small cystic spaces, and enlarged astrocytic nuclei. Celloidin, haematoxylin, van Gieson. $\times 375$.

all substances are greatly reduced in amount, the figures being even lower than the normal for the the age of this child. However, the cortex shows less variation from a normal brain of the corresponding age, but there is some loss of all substances except cerebrosides, which are very slightly increased above the normal.

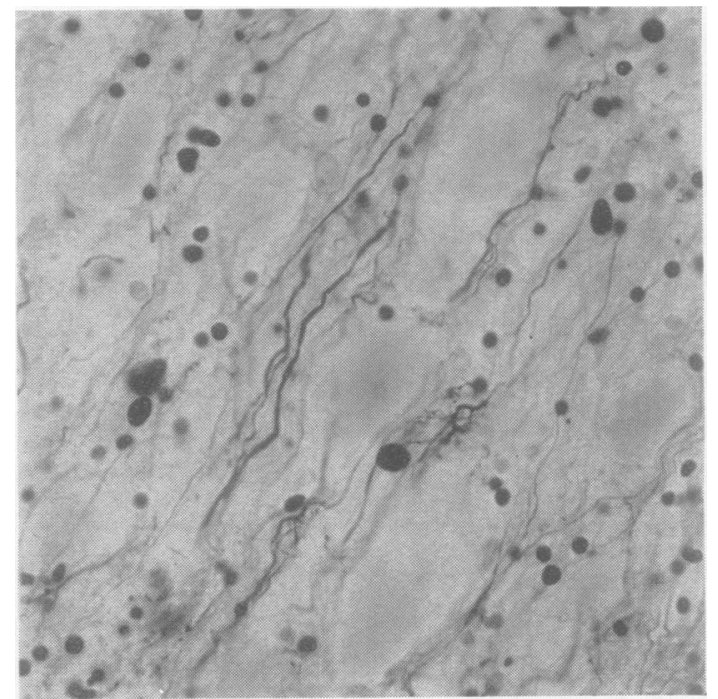

FIG. 11.-Parietal deep white matter showing the axons running obliquely across the section in the tissue between the cysts. Celloidin, Gros-Bielschowsky, $\times 375$.

It is specially noteworthy that the more normal central white areas as judged macroscopically give very similar results to those of the demyelinated zones. The figures obtained are in fact almost exactly identical with those found in a foetus of 6 to 7 months (Cumings). $f$

Comment.-Although only some six cases of this disease have been described since the first by Canavan (1931) the clinical amd pathological resemblance to each other is striking. Five patients have died and in four the brain has been unusually large; in one the size was not noted. All have shown the marked spongy change.

It is quite probable that there have been other cases, which have not been recorded, because of the cystic change which may have been considered to be due to post-mortem artefact. This possibility, which has been considered by previous authors, can be definitely excluded in our case by the fact that the necropsy was carried out three hours after death.

There are perhaps two points of special interest in this case. The first concerns the pathogenesis of the condition. van Bogaert and Bertrand (1949), who call the condition "familial idiocy due to spongy degeneration of the nervous system ", consider that it is a degenerative condition, probably abiotrophic because of its possible familial character and slow progressive course. They consider that it corresponds exactly to a chronic oedema of the 


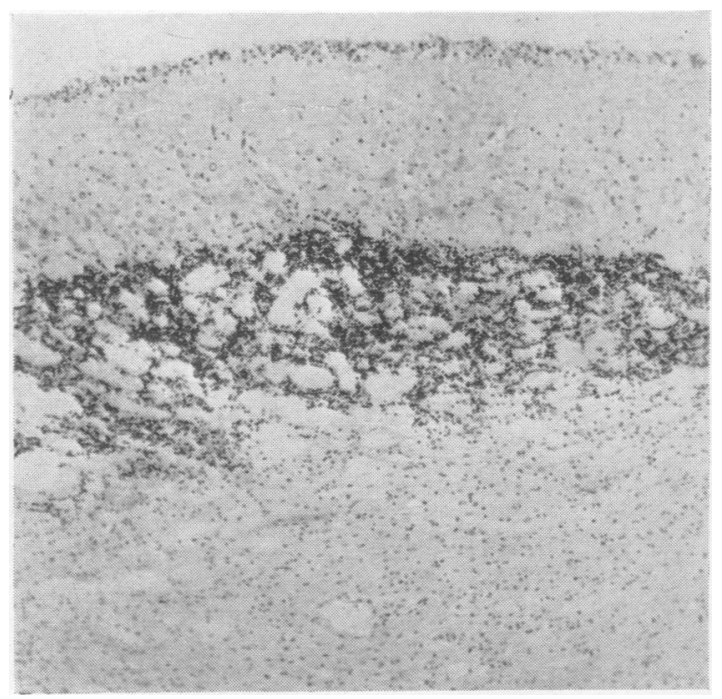

FIG. 13.-Cerebellar hemisphere showing persistence of the external granular layer, cystic changes in the Purkinje cell and granule cell layers, and in the white matter, with displacement of the Purkinje cells towards the pia mater. Celloidin, haematoxylin, van Gieson, $\times 60$.

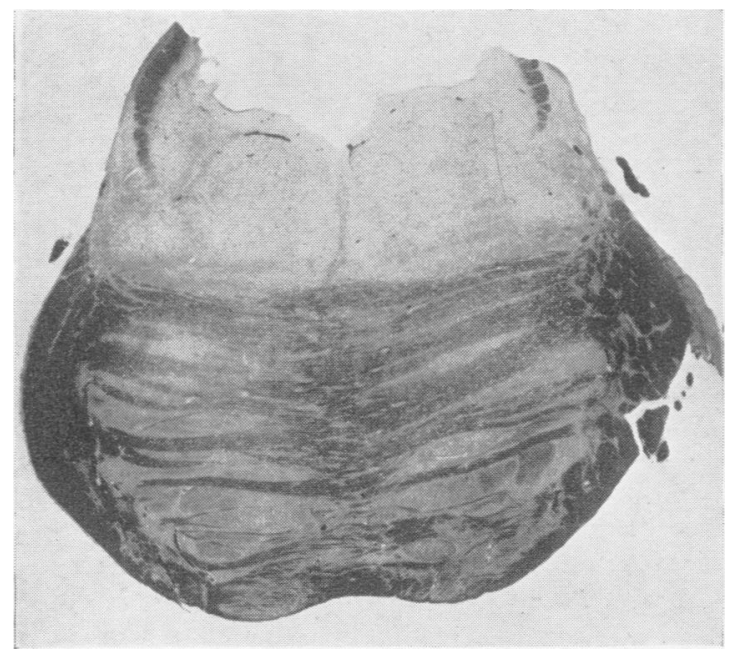

Fig. 15.-Junction of pons and midbrain, showing the well myelinated superior cerebellar peduncles and transverse fibres of the pons. Celloidin, Loyez, $\times 3 \cdot 5$.

grey and white matter. A similar view of the cause of the condition is given by Meyer (1950), who considered that there was an infiltration of the tissues by abnormal serous fluid; that there was, in fact, oedema.

The chemical analysis suggests very strongly that myelination in the white matter of the brain

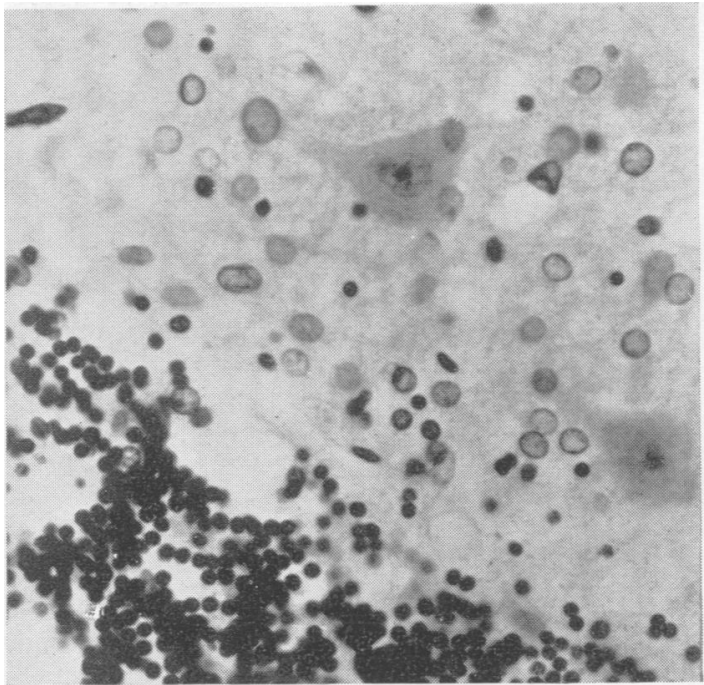

FIG. 14.-Cerebellar hemisphere showing displacement of Purkinje cells and broadening of the Bergmann cell astrocytic layer, the nuclei of which are increased in number and size. Celloidin, haematoxylin, van Gieson, $\times 375$.

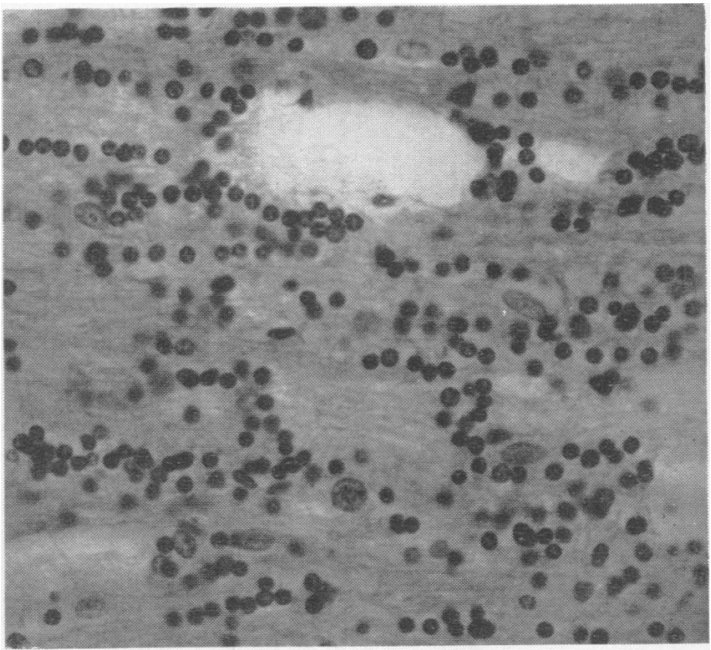

Fig. 16.-Transverse fibres of the pons which are well myelinated but cystic. The astrocytic nuclei are increased in size. Celloidin, Loyez, $\times 375$.

in this condition does not take place properly and that it stops in foetal life. The raised water content could be compatible with oedema of the brain, but if this had taken place during extra-uterine life the lipids, although lower than normal, would be considerably higher than were found. Further, the cortex and basal ganglia in this case do not show 
the same degree of oedema or loss of lipids as does the white matter, and are in fact almost normal for the age of this child.

The second point is whether this type of disease process should be included in a classification of diffuse demyelinating sclerosis such as that put forward by Greenfield (1950).

To the naked eye there is such a similarity between the brain in the condition called "spongy degeneration" by van Bogaert and Bertrand, and in conditions commonly accepted as diffuse demyelinating sclerosis, that its incorporation in such a classification is possible. However, our findings reveal that the widespread histological deficiency of myelin is associated with gross loss of all lipids chemically, which is compatible with a failure of maturation rather than with destruction of formed myelin. It seems unreasonable therefore to include this condition in the category of diffuse demyelinating sclerosis.

\section{Case B (Pelizaeus Merzbacher Type)}

Clinical History.-E. W. was a girl whose family history was very difficult to obtain. She was known to be the sixth child. It has not, up to date, been possible to obtain the medical history of the other five children. Her father was nine years in a mental hospital. She spoke at $1 \frac{1}{2}$ years of age, walked at $3 \frac{1}{2}$ years, and was clean in her habits at 4 years. At the age of 7 years 3 months she was well grown and normal in appearance but her mental age was about 3 years. At the age of 12 years when re-examined she had deteriorated both physically and mentally. She was much more spastic, choreiform movements of armearempanied voluntary movement. speech was very dysarthric. At the age of 13 her mental age was between 4 and 5 , she had occasional enileptic fits, and she was doubly incontinent. She died shortly before her fourteenth birthday.

\section{Post-mortem Findings in Case B}

Dr. L. Phillips performed the necropsy. The brain showed moderate atrophy with ventricular dilatation. The white matter of the cerebral hemispheres had a greyish appearance with creamy coloured flecks and streaks (Fig. 17), due to small residual foci of myelin in largely demyelinated tissue (Fig. 18).

Histological Findings. - The histological findings are limited to a description of those regions which were examined chemically.

Parietal Region.-The leptomeninges and leptomeningeal vessels appeared healthy. The cortex did not show any significant abnormality of cytoor myelo-architectonics. The white matter, including the subsulcine regions, was poorly myelinated except around the larger blood vessels where myelin fibres were present (Fig. 19). The appearances were similar in sections stained by the Weigert-Pal method and in Loyez (celloidin) preparations. Nerve fibres were, however, numerous in all regions. Swellings upon the myelin sheaths were occasionally present but were not seen on the axons. Sudanophilic lipid was present in occasional phagocytes associated with a few lymphocytes around the larger blood vessels. Oligodendroglial nuclei were closely related in number to the muelinated nerve fibres, being fairly numerous around such larger blood vessels as were clothed in myelinated nerve fibres and being sparse between the blood vessels (Fig. 20). Astrocyte nuclei were only a little more numerous than normal. They were not larger than normal and the cytoplasm around them was not increased in amount. Astrocytic fibres, were, however numerous and ran in an isomorphic fashion.

Basal Ganglia.-The nerve cells appeared normal in number and appearance in both the putamen and the pallidum. The myelinated nerve fibres were very slightly reduced in number and some showed varicosities. The number of oligodendroglial nuclei was definitely reduced. The astrocytes were slightly increased in number, sometimes occurring in pairs. Their perinuclear cytoplasm was not increased in amount but most of them had developed astrocytic fibrils in their processes. The perivascular spaces were enlarged and contained occasional globules of myelin but no cells.

Chemical Results.-The results that have been found in this brain are illustrated in Table II. It

TABLE II

LIPID CONTENT OF BRAIN * IN PELIZAEUS MERZBACHER TYPE

\begin{tabular}{|c|c|c|c|c|}
\hline & & & Cerebral White & Cerebral Cortex \\
\hline $\begin{array}{l}\text { Total phospholipi } \\
\text { Monoamino phos } \\
\text { Sphingomyelin } \\
\text { Lecithin } \quad . \\
\text { Kephalin . . } \\
\text { Total cholesterol } \\
\text { Free cholesterol } \\
\text { Cerebroside ... } \\
\text { Water } \quad .\end{array}$ & $\begin{array}{l}\text { holipin } \\
\ldots \\
\ldots \\
\ldots \\
\ldots \\
\ldots \\
\ldots\end{array}$ & $\begin{array}{l}\cdots \\
\cdots \\
\cdots \\
\cdots \\
\cdots \\
\cdots\end{array}$ & $\begin{array}{l}2 \cdot 1 \dagger \\
1 \cdot 37 \\
0 \cdot 73 \\
1 \cdot 0 \\
0 \cdot 37 \\
1 \cdot 5 \\
1 \cdot 5 \\
0 \cdot 99 \\
84 \cdot 3\end{array}$ & $\begin{array}{l}3 \cdot 2 \\
2 \cdot 0 \\
1 \cdot 2 \\
1 \cdot 36 \\
0.64 \\
1 \cdot 83 \\
1 \cdot 50 \\
1.06 \\
82.8\end{array}$ \\
\hline
\end{tabular}

* Brain formalin fixed for two weeks.

$\dagger$ Results in g./100 g. fresh tissue.

is seen in the white matter that while there is an increased water content all the other substances are diminished in amount. The cortex shows a less severe loss of phospholipins with a normal water content, but some cholesterol esters are 


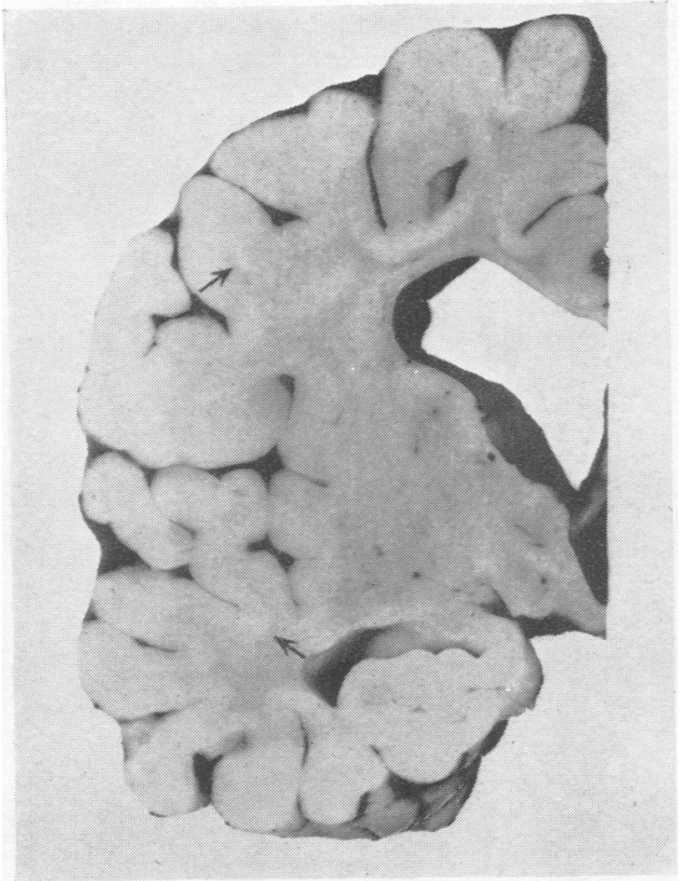

FIG. 17.-Posterior aspect of coronal slice at the level of the corpora mammillaria, showing the greyish appearance of the white matter apart from creamy coloured flecks and streaks (arrows) of myelin.

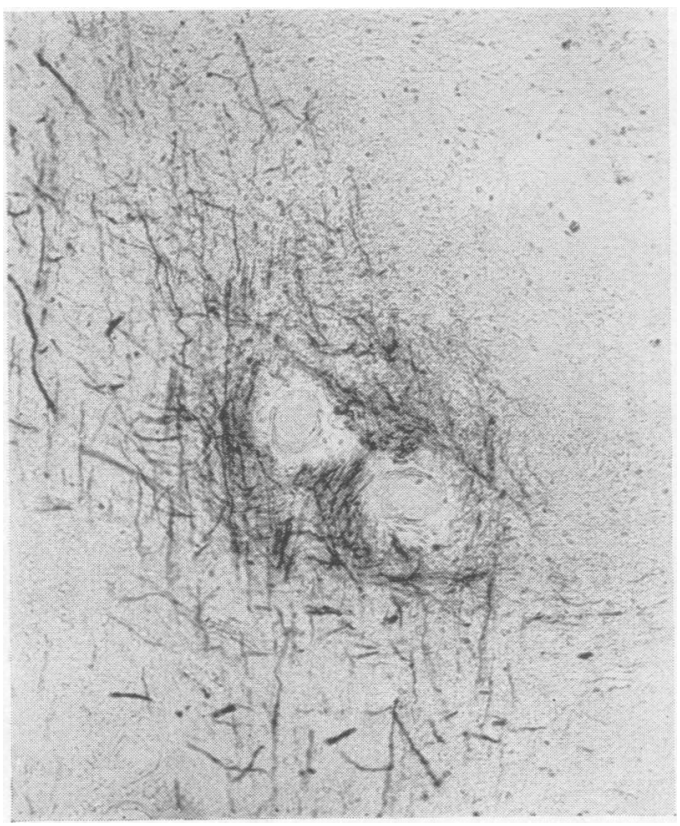

FIG, 19.-Parietal white matter, stained for myelin, showing perivascular sparing of the myelin. Celloidin, KultschitskyPal, $\times 110$.

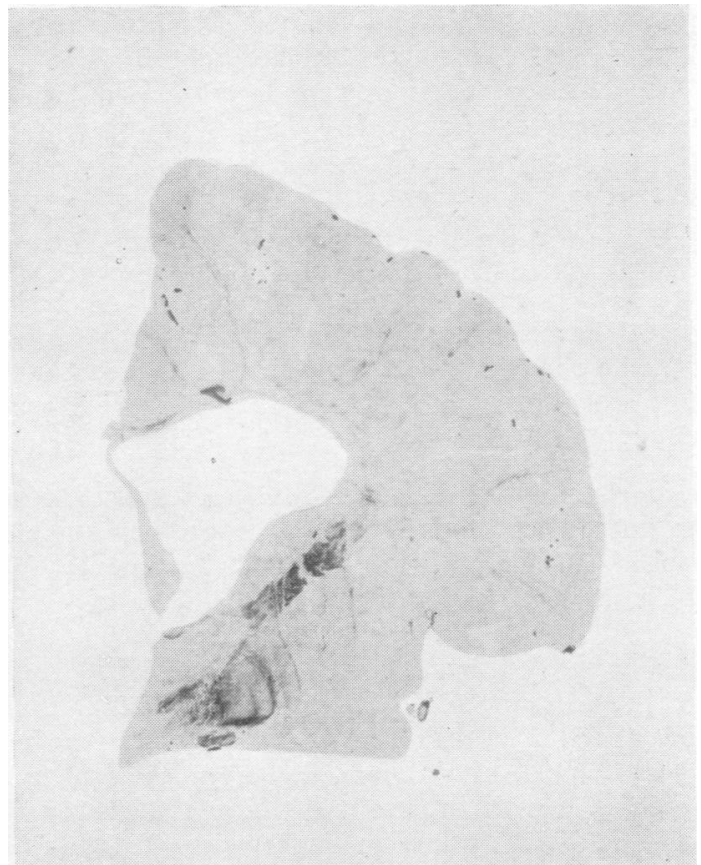

Fig. 18.-Coronal section at the level of the corpora mammillaria stained for myelin. Note that the subsulcine fibres are not particularly spared but that the internal capsule, the optic tract, and the fibres of the lentiform nucleus are well myelinated. Celloidin, Kultschitsky-Pal.

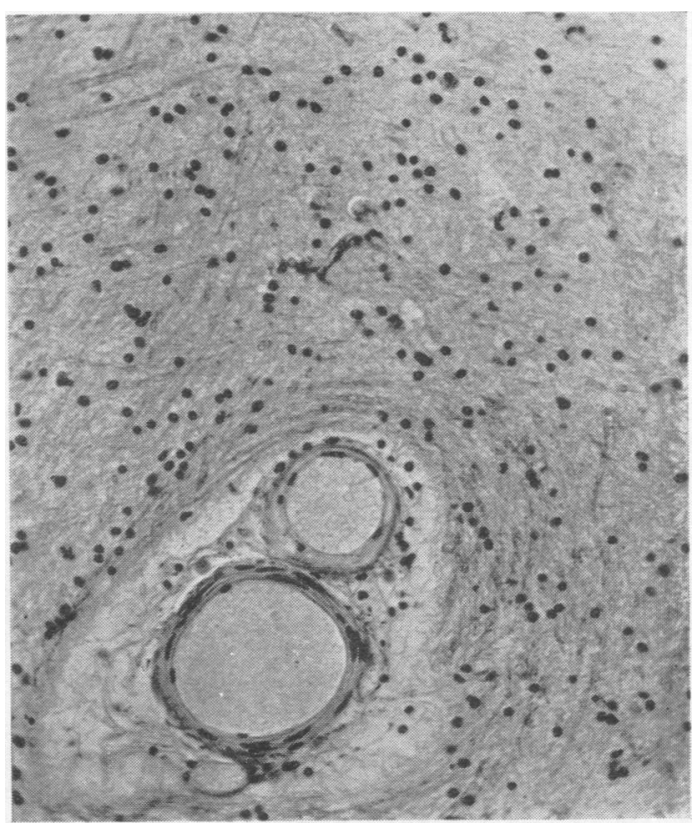

Fig. 20.-Parietal white matter showing a few phagocytes around the blood vessels, perivascular preponderance of myelin and oligodendroglia, and little visible change in the astrocytes. Celloidin, haematoxylin, van Gieson, $\times 215$.

FIGs. 17-20.-Degeneration of the Pelizaeus-Merzbacher type as seen in Case B. 
present here as indicated by the difference between the amounts of free and total cholesterol.

The absence of cholesterol esters in the white matter suggest that active demyelination is not occurring here and this, taken in conjunction with the generalized reduction of all lipids to a level found in the brain of a child of not more than 2 years of age, suggests that myelination had proceeded normally to about this age, after which normal development had not taken place. However, the changes found in the cortex do show that some active process of demyelination is at work in this region of the brain.

Comment.-Apart from the lack of knowledge of the history of other members of the family this case is similar to those described clinically by Pelizaeus (1885) and the one described histologically by Merzbacher (1910). It is also similar to the cases described by Bielschowsky and Henneberg (1928), Liebers (1928), Bodechtel (1929), and Löwenberg and Hill (1933).

The clinical, histological, and chemical evidence presented here is in favour of the white matter of the brain of case B having developed normally until about the age of 2 years. The chemical analysis revealed no breakdown products of myelin apart from the presence of cholesterol esters in the cortex, neither did the histological examination show any significant amount of sudanophilic fat still present.

\section{Case C (Krabbe Type)}

Clinical History.-D. B. (N.H. No. 21280), a boy, had three healthy older siblings. The family history contains no note of any similar case. The mother had a healthy pregnancy and delivery. The child's development was retarded. He sat up at 10 months, slid around the floor at 1 year, but never learned to walk properly. At 18 months he talked, developed normally in this respect, and took an active, intelligent, normal interest in everything. A slight left hemiparesis was noticed at an early age possibly from birth. At 15 months the hemiparesis became worse after measles. At 2 years 1 month he developed epileptic attacks involving the left side of his bodv-three or four times a day. He was admitted to Charing Cross Hospital under the care of Dr. Doyne Bell where he was found to have a left spastic hemiplegia. Radiographs of the skull were normal. Cerebrospinal fluid protein was $65 \mathrm{mg}$. per $100 \mathrm{ml}$; ; cells, chlorides, and sugar were normal. The fundi were normal and the intelligence only slightly retarded. He was transferred to the National Hospital, Queen Square, under the care of Dr. E. Arnold Carmichael. The special senses appeared normal. The cranial nerves were normal apart from slight right facial weakness: motor system spastic diplegia with flexed upper and extended lower limbs : reflexes were absent because of the degree of spasticity : the plantar responses were extensor : sensation showed a response to pin prick. Radiographs of the skull were normal. An E.E.G. (Dr. W. A. Cobb) showed highvoltage, very slow waves, maximal on the right but present on the left also, without any indication of their focus of origin.

The C.S.F. was clear and colourless, with 2 cells per c. $\mathrm{mm} ., 180 \mathrm{mg}$. protein per $100 \mathrm{ml}$., and a Lange curve of 0012111000 .

A ventriculogram (Dr. D. Sutton) showed slight symmetrical dilatation of the lateral, third, and fourth ventricles.

The patient was discharged home. He remained remarkably well for about 11 months and then developed bronchopneumonia from which he died at the age of 3 years 2 months.

\section{Post-mortem Findings in Case C}

Dr. D. Haler performed the necropsy. Externally the child appeared adequately nourished. The cause of death was a terminal bronchopneumonia. Apart from the brain the other organs did not show any significant abnormality.

Central Nervous System.-Excess of cerebrospinal fluid was present on the surface of the brain, which was extremely congested and showed some degree of atrophy.

Only the brain was available for examination and this weighed $800 \mathrm{~g}$. (normal 1,141 g.). The cerebellar hemispheres weighed $70 \mathrm{~g}$., the brain-stem $10 \mathrm{~g}$., and the cerebral hemispheres $720 \mathrm{~g}$. Externally the brain appeared to be slightly and symmetrically small, but no gross cortical atrophy was apparent. On section (Figs. 21 and 22) there was widespread replacement of the white matter of both cerebral and cerebellar hemispheres by a pinkish tissue which was slightly translucent except in the frontal lobes, where it was slightly granular. In the posterior parietal region the abnormality of the white matter was not always so complete peripherally as in the frontal lobes. The subsulcine fibres appeared normal, as also did the inferior third of the body of the corpus callosum, the fornix and the white matter of the hippocampal gyri, the optic tracts but not the optic radiations, the septum pellucidum, the striate fibres running between the caudate and the lentiform nuclei, and the subcortical white matter interior and medial to the anterior part of the corpus striatum. The lateral and third ventricles were slightly dilated. The cerebellum, which was very firm, showed extensive pinkish gelatinous replacement of the deep white matter with apparent sparing of the capsular fibres of the dentate nuclei. The midbrain looked poorly myelinated. The tegmentum of the pons appeared well myelinated but the pons proper appeared 
demyelinated. In the medulla oblongata the pyramids appeared demyelinated but were not shrunken. The rest of the medulla appeared healthy.

Histological Findings. - It was at once apparent that the white matter of the brain showed widespread replacement of myelin (Fig. 23) by inflammatory cells, the most prominent of which were "endothelioid" cells or "globoid" bodies (Fig. 30), as described by Krabbe (1916) and Collier and Greenfield (1924).

White Matter.-The pathological process was bilaterally symmetrical. In the cerebrum it affected especially the white matter, with relative sparing of the subsulcine fibres. The fornix, the alveus, the white matter of the hippocampal gyrus, and the myelinated fibres in the thalamus and lentiform nucleus on either side were spared. The optic nerves, chiasm, tracts, and radiations were involved, although myelinated fibres were still present in these structures.

In the cerebellum the white matter of the vermis appeared healthy. In the hemispheres the process increased in severity as the nerve fibres of the folia approached the deeper white matter, where the process was well marked. The amiculum of each dentate nucleus and the superior cerebellar peduncles appeared healthy. The middle cerebellar peduncles were affected.

In the brain-stem the superior cerebellar peduncles appeared healthy. The cerebral peduncles and pyramids contained very few myelinated fibres and like the internal capsules were affected by the process, but globoid bodies were not numerous. The middle cerebellar peduncles and the transverse pontine fibres were severely involved. The inferior cerebellar peduncles did not contain quite as many myelinated fibres as usual. The medial lemnisci were very poorly myelinated except in their posterior parts. The lateral lemnisci, the dorsal tegmental tracts, the fifth nerve complexes, and the fasciculi solitarius appeared healthy. The olivo-cerebellar fibres were less numerous than normal and were the site of a globoid body reaction.

The spinal cord was not available.

Gray Matter.-In contrast to the white matter the gray matter was relatively healthy. In the cerebral cortex the number of nerve cells appeared to be slightly fewer than normal. There was no astrocytic abnormality. Radial and tangential myelinated fibres were present, especially in the line of Gennari. The caudate and lentiform nuclei appeared normal. In many regions of the thalamus there was considerable astrocytic hyperplasia with- out marked cell loss. In the cerebellum, in the cortex of the hemispheres there was moderate loss of granule cells and of Purkinje cells, many of which showed "torpedo" swellings upon their axons. The cortex of the vermis appeared healthy. The dentate nuclei appeared healthy. In the brain-stem the substantia nigra appeared healthy as did the cranial nerve nuclei at the levels examined. Many of the nerve cells of the pontile nuclei had disappeared. This feature was associated with slight local astrocytic hypertrophy and hyperplasia, but very little glial fibre formation. Some nerve cells had disappeared from the inferior olivary nuclei with slight fibrous gliosis.

Detailed Histology of the White Matter.-The process in the white matter of the cerebrum and cerebellum, although essentially of the same nature, did not appear to be of the same age in all regions. In the medial part of the white matter of the frontal lobes and in the cerebellar hemispheres the process appeared to be most recent, for here there were a considerable number of myelinated nerve fibres, many compound granular corpuscles containing sudanophilic lipid and anisotropic elongated crystalline material (nossibly cholesterol esters) and very little astrocytic fibre formation. In other regions, such as the temporal lobes, there were few myelinated nerve fibres, sudanophilic lipid was not present, and astrocytic fibre formation was slight. Lastly there were regions where the process appeared to be the oldest, as in the superior part of the frontal lobes, in the parietal lobes and especially in the occipital lobes, where the cellular reaction was generally less and the astrocytic gliosis was intense. Here the gliosis extended into the subsulcine fibres, which were less spared than in regions where the process appeared to be more recent.

Myelin.-In the deeper white matter some myelinated nerve fibres were usually present, except perhaps in the oldest affected regions. In the other regions isolated fine myelinated fibres could quite often be seen. There was no evidence that the loss of myelin was noticeably greater than the loss of nerve fibres. Where myelinated fibres were more numerous, as they were in the frontal lobes, oligodendroglial nuclei were quite numerous.

Cellular Response: "Free" (Myelin) Bodies.-The cellular response (Fig. 31) was characterized by the presence of " free bodies", called " myelin bodies" by Ferraro (1927). These were ill-defined, structureless, or faintly granular, sometimes globular masses, without attendant nuclei (Fig. 24), but with staining characteristics similar to the material within the globoid bodies (vide infra) although it stained less 


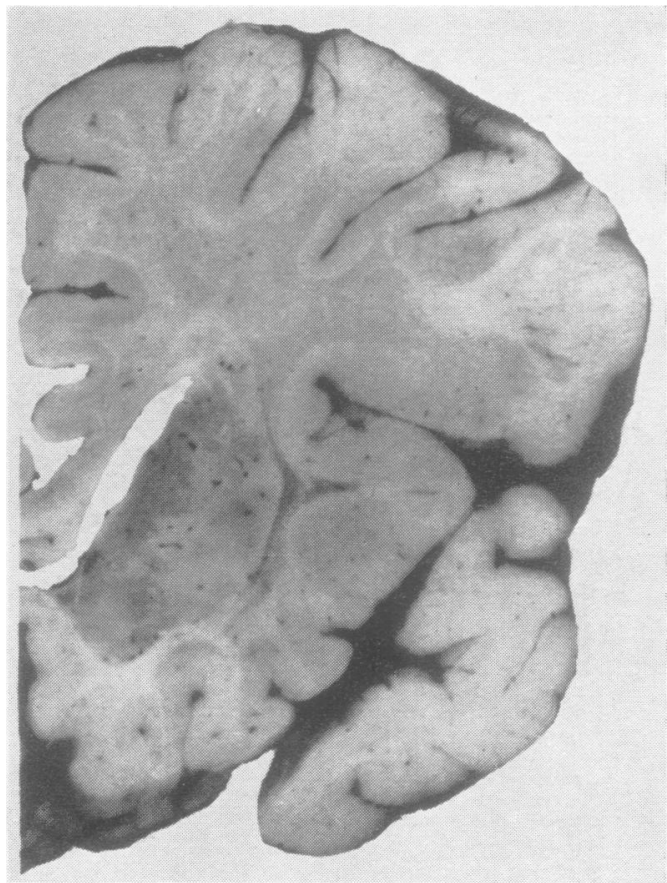

FIG. 21.-Posterior aspect of coronal section through posterior frontal region.

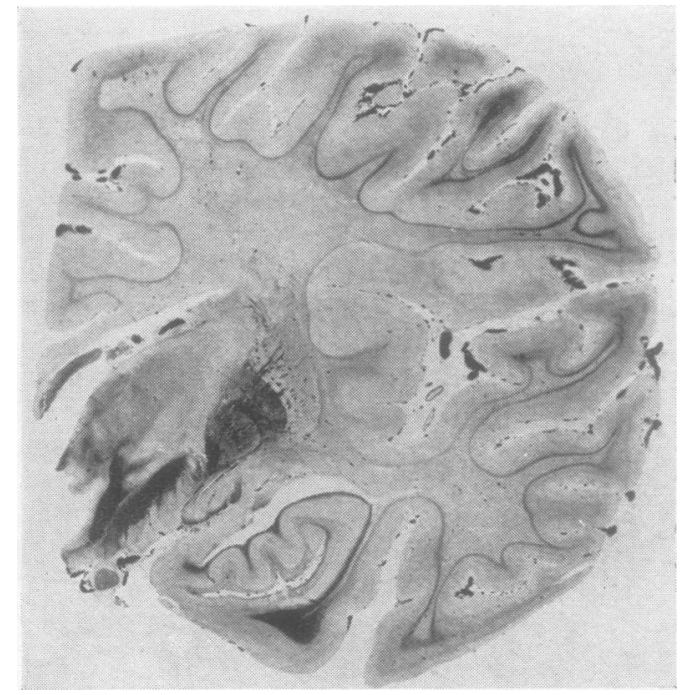

FIG. 23.-Coronal section at the level of the corpora mammillaria (the brain being somewhat distorted), stained for myelin. Note the extensive loss of myelin from the white matter with sparing of the $U$ fibres. Celloidin, Loyez.

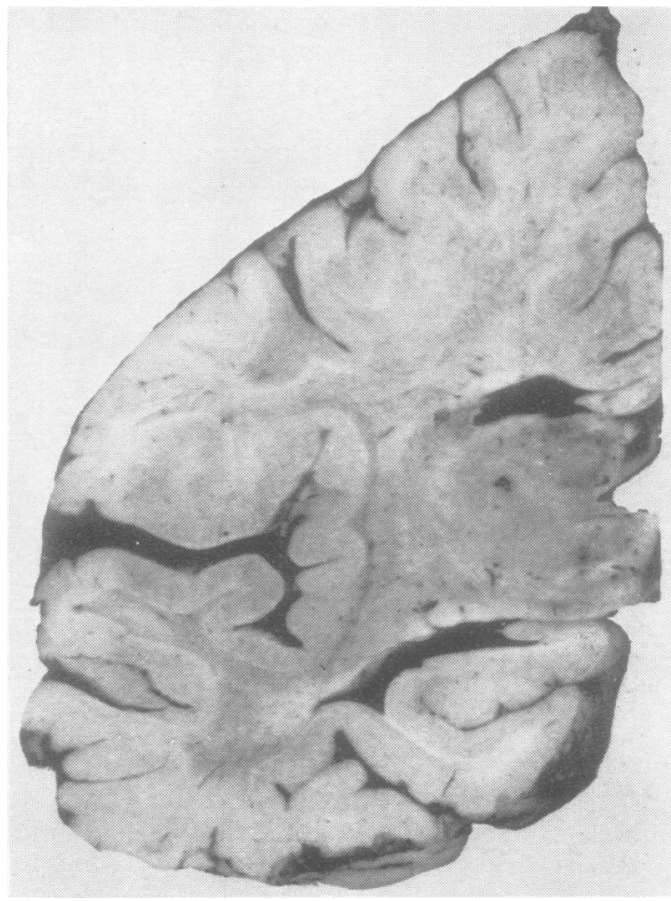

FIG. 22.-Posterior aspect of coronal section at the level of the red nucleus.

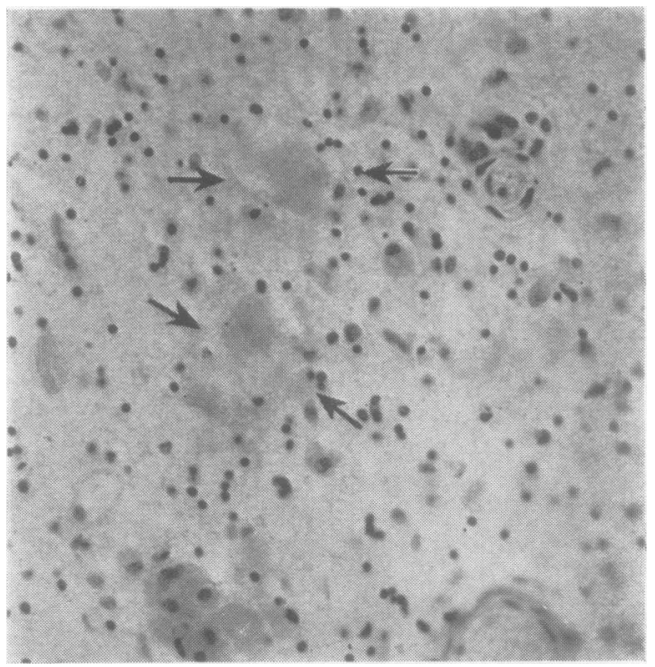

FIG. 24.-Frontal white matter. The arrows point to the illdefined masses of material without attendant nuclei. Celloidin, mucicarmine, $\times 250$.

Figs. 21-34.-Degeneration of Krabbe type as seen in Case C. 


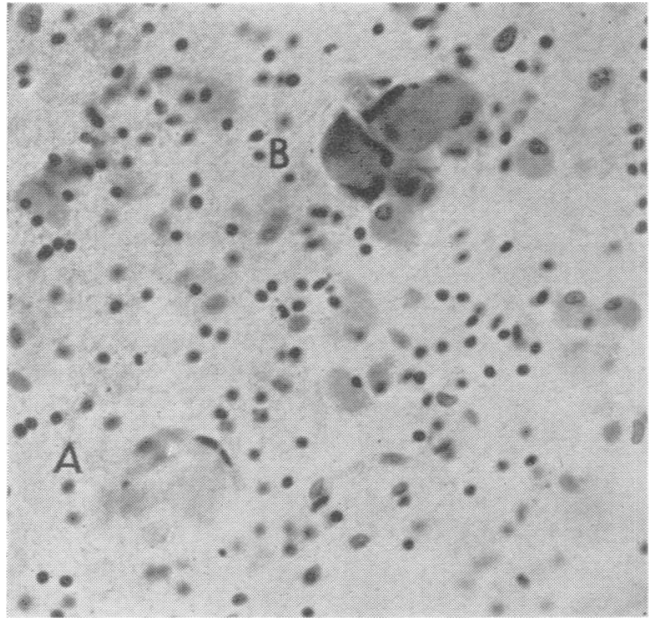

Fig. 25.-Frontal white matter. At $\mathbf{A}$ is a mass of material similar to that seen in Fig. 24 but along one border are elongated nuclei. At $B$ are two globoid cells. Celloidin, mucicarmine, $\times 250$

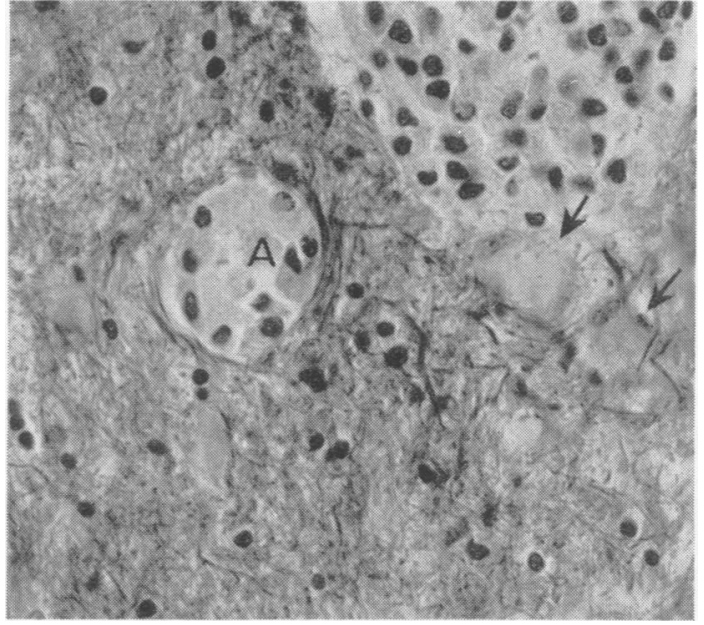

Fig. 26.-Parietal white matter, stained for astrocytic fibrils which can be seen surrounding a group of small globoid bodies at $\mathbf{A}$. The arrows point to reactive astrocytes. Celloidin, Mallory's phosphotungstic acid haematoxylin, $\times 425$.

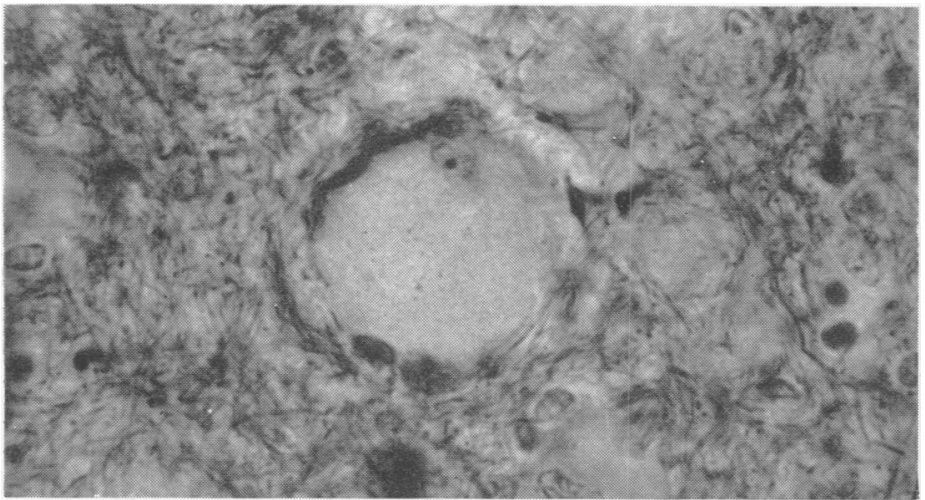

FIG. 27.-Parietal white matter stained for astrocytic fibrils which can be seen surrounding a large globoid body. The reaction is similar to that round a foreign body. Mallory's P.T.A.H., $\times 425$.

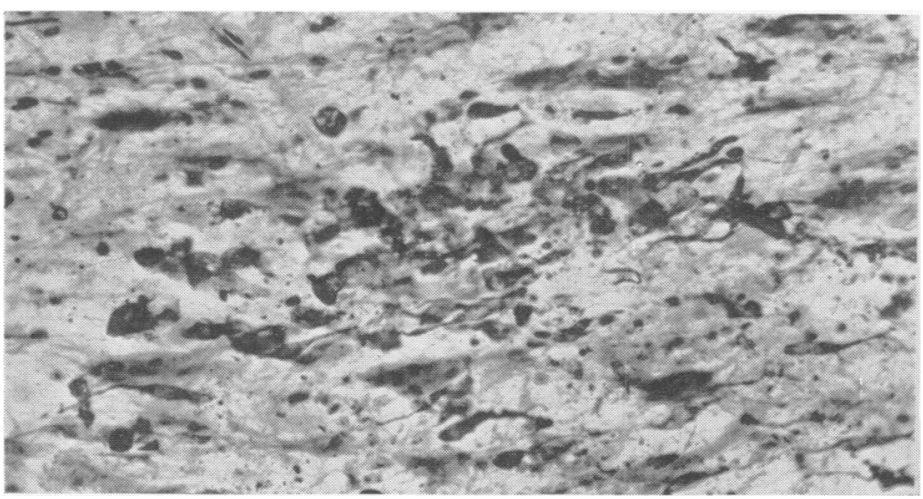

FIG. 28.-Corpus callosum. Near the centre of the picture are some masses of very faintly P.A.S. positive, abnormal material around which microglia are radially arranged. Frozen, Hortega microglial impregnation and P.A.S., $\times 260$.

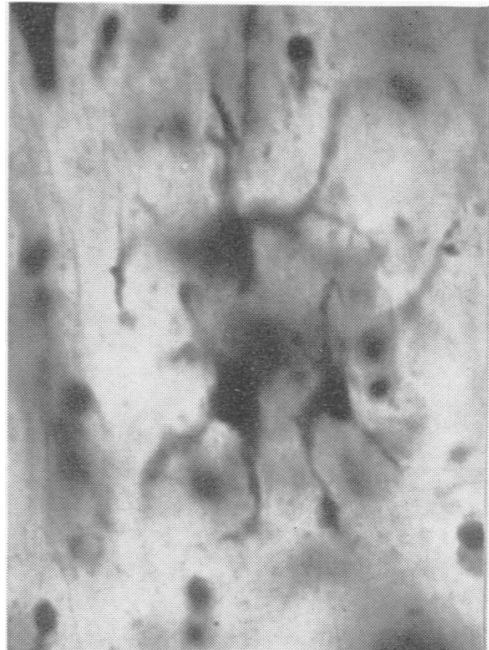

Fig. 29.--Parietal white matter. Another stage in the envelopment of abnormal material by microglia. Frozen, Hortega microglia impregnation, $\times \mathbf{7 5 0}$. 
strongly. Some similar masses had one or two nuclei situated at the periphery (A. Fig. 25) and were then intermediate between the free bodies and the globoid bodies.

Cellular Response: "Globoid Bodies".-The presence of "globoid bodies" was the second characteristic of the cellular response. These cells, rounded or flattened by mutual pressure, were of two main types. They were either small with one or two nuclei (Fig. 26) or large (from $20 \mu$ diameter to $50 \mu \times$ $40 \mu$ diameters) and multinucleated (usually about six nuclei, sometimes as many as 15 nuclei) (Fig. 27). In general, the larger the globoid body the more numerous were the nuclei, which had a well defined nuclear membrane and a few scattered granules of chromatin. The nuclei lay at the periphery of a protoplasmic mass and were rounded, ovoid, or elongated, according to the plane of section. In general the size of the nuclei (greatest diameter about $11 \mu$, least about $3 \mu$ ) was less than that of the nuclei of adjacent reactive astrocytes, some of which were as large as $15 \mu \times 7 \mu$. The protoplasmic mass, often finely granular and denser peripherally, was sometimes vacuolated.

The glohoid bodies were more numerous towards the junction of white and gray matter, where the large ones were usually solitary and only rarely related to blood vessels. The smaller ones were found in groups, either remote from or encircling the small blood vessels, where they were associated with a small number of lymphocytes (Figs. 30 and 31). In the deeper parts of the white matter, in what appeared to be older lesions, very few of the larger bodies were present and the smaller bodies were fewer with a relative preponderance around the blood vessels.

The staining reactions of the material within the globoid bodies were as follows :

\begin{tabular}{|c|c|c|}
\hline \multicolumn{2}{|c|}{ Stain } & Staining Reaction \\
\hline \multicolumn{2}{|c|}{ Haematoxylin van Gieson } & $\begin{array}{l}\text { A greyish colour with a faint tinge of } \\
\text { yellow }\end{array}$ \\
\hline Mucicarmine & $\cdots$ & Faint pink staining \\
\hline \multicolumn{2}{|c|}{$\begin{array}{l}\text { Toluidine blue mounted in } \\
\text { "Microil " }\end{array}$} & Bluish, no metachromasja \\
\hline P.A.S. & . & Positive, pink colour, finely granular \\
\hline Congo red & $\cdots$ & Negative for amyloid \\
\hline Sudan black B & $\cdots$ & $\begin{array}{l}\text { Generally brownish with some fine } \\
\text { black grannes }\end{array}$ \\
\hline Sharlach $\mathbf{R}$ ha & matoxylin & $\begin{array}{l}\text { Diffuse pale rose pink colour. In } \\
\text { regions where the pathological process } \\
\text { appeared to be most recent and the } \\
\text { white matter appeared to be actively } \\
\text { disintegrating, some of the large as } \\
\text { well as many of the small globoid } \\
\text { bodies contained droplets of sudano- } \\
\text { philic material. }\end{array}$ \\
\hline
\end{tabular}

Reaction of the Astrocytes.-In the white matter there was a widespread reaction consisting in the more recent lesions, of hypertrophy and hyperplasia with scanty glial fibre formation, and in the older lesions, such as in the occipital lobes, of dense fibrous gliosis associated with swollen astrocytes. The cytoplasm of the astrocytes did not have the same staining reactions as that of the globoid bodies (Fig. 30). Where astrocytic fibres and globoid bodies were close together the astrocytic fibres appeared to surround the globoid bodies and not to emerge from them (Figs. 26 and 27). There was no evidence of transitional forms between the astrocytes and the globoid bodies.

Reaction of Phagocytic Cells.-There was moderate activity of phagocytic cells in the deeper layers of the cortex, where the majority of the cells appeared to be microglia with thickened and retracting processes. There was greater activity in the subsulcine regions and especially in the superficial parts of the white matter where phagocytes were reacting both to sudanophilic material and to P.A.S.-positive material. It was not possible to distinguish between microglia and adventitial phagocytes. In regions where myelinated nerve fibres appeared to be actively disintegrating, phagocytic cells distended with sudanophil narticles and anisotronic crystalline material were visible. The response of the phagocytic cells to the P.A.S.-positive material was clearly seen in frozen sections impregnated with silver for microglia and counterstained with P.A.S. The earliest stage appeared to be a radial arrangement of microglia (or microglia-like cells) around faintly staining and not clearly delimited P.A.S.positive material (Fig. 29). Later stages consisted of envelopment of large or small masses of this material by the phagocytic cells, whose nuclei and processes became arranged around the periphery of the material, which became more clearly delimited and more strongly P.A.S. positive (Figs. 29, 32, 33, 34). A large mass, encompassed by several phagocytic cells, such as that shown in Fig. 34, would, if stained by haematoxylin van Gieson, be identical with a globoid body (B. Fig. 25).

Reaction of the Blood Vessels.-There did not appear to be much reaction on the part of the cellular components of the vessel walls, even in regions where the process appeared to be most active. There was, however, a striking similarity between the size, shape, and staining qualities of the nuclei of the walls of the small vessels and those of the phagocytic cells enclosing P.A.S.-positive material which were present in the adjacent perivascular spaces. 


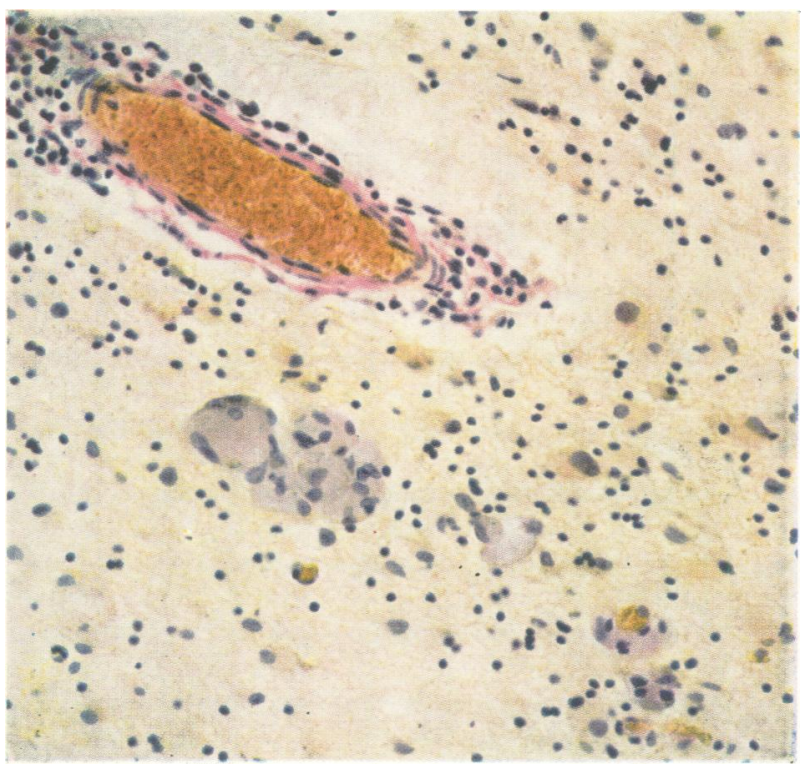

Fig. 30

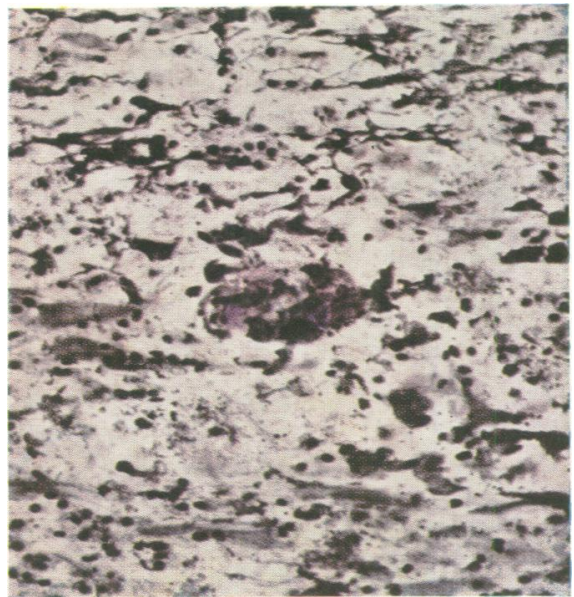

FIG. 32

Fig. 30.-Frontal white matter. Near the centre are one large and several small globoid bodies with greyish cytoplasm. Many reactive astrocytes with orange cytoplasm are visible. The cells around the venule are chiefly lymphocytes. Celloidin, haematoxylin, van Gieson, $\times 250$.

FIG. 31.-In this section the P.A.S.-positive material can be seen in solitary large globoid bodies and in small globoid bodies grouped either remote from or around small blood vessels. Celloidin, P.A.S., haematoxylin, $\times 175$.

FIGs. 32, 33, 34.-Stages in the envelopment of P.A.S.-positive material by phagocytic cells. The material becomes more clearly delimited and more strongly P.A.S. positive. Compare the body indicated by the arrow (Fig. 34) with a globoid body (B. Fig. 25). Frozen, Hortega microglia impregnation and P.A.S., $\times 400$.

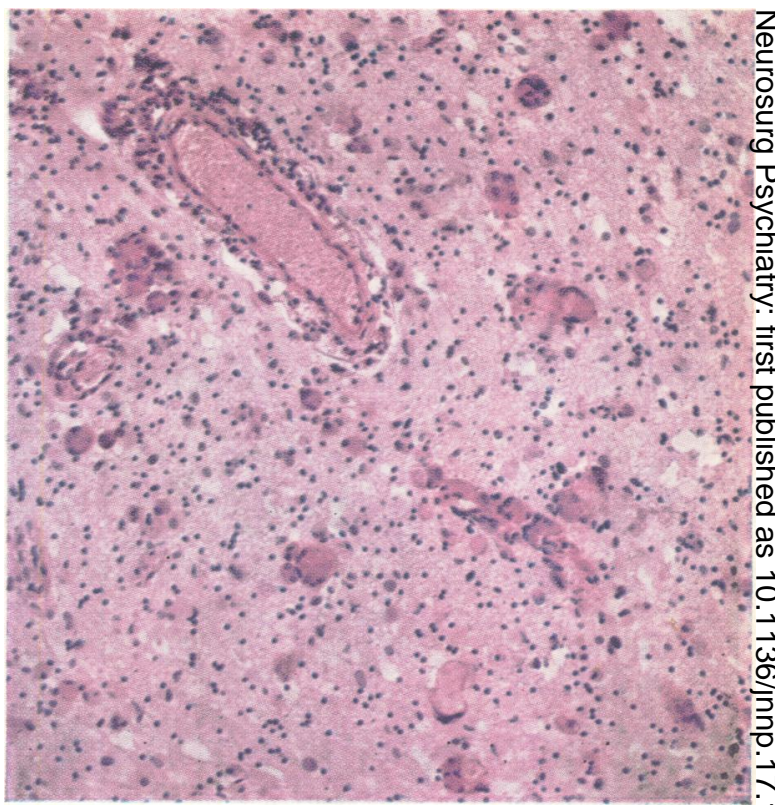

Fig. 31

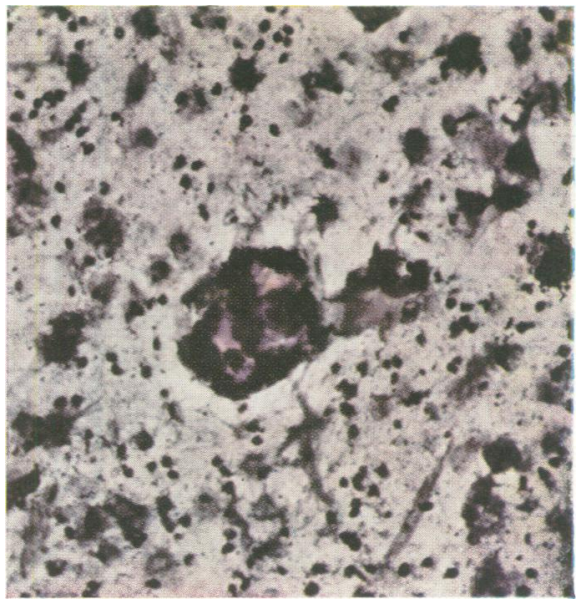

FIG. 33

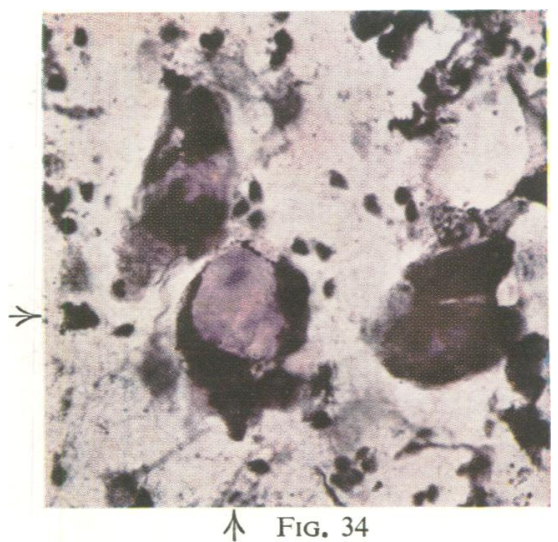

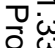

هㅇำ

迥

ס्र

을 동

흘 
Chemical Results.-Table III gives the results obtained in the case in which globoid bodies were

TABLE III

LIPID CONTENT IN BRAIN * IN GLOBOID BODY TYPE

\begin{tabular}{|c|c|c|c|c|c|}
\hline & & & $\begin{array}{c}\text { Cerebral } \\
\text { White }\end{array}$ & $\begin{array}{c}\text { Cerebral } \\
\text { Cortex }\end{array}$ & $\begin{array}{c}\text { Basal } \\
\text { Ganglia }\end{array}$ \\
\hline $\begin{array}{l}\text { Total phospholip } \\
\text { Monoamino phos } \\
\text { Sphingomyelin . } \\
\text { Lecithin } \\
\text { Kephalin } \\
\text { Total cholesterol } \\
\text { Free cholesterol } \\
\text { Cerebroside .. } \\
\text { Water .. }\end{array}$ & $\begin{array}{l}\text { lipin } \\
\ldots \\
\ldots \\
\ldots \\
\cdots \\
\ldots \\
\ldots\end{array}$ & $\begin{array}{l}\cdots \\
\cdots \\
\cdots \\
\cdots \\
\cdots \\
\cdots \\
\cdots\end{array}$ & $\begin{array}{c}1 \cdot 3 \dagger \\
0.94 \\
0 \cdot 36 \\
0 \cdot 21 \\
0 \cdot 73 \\
0 \cdot 69 \\
0 \cdot 62 \\
3 \cdot 7 \\
84 \cdot 2\end{array}$ & $\begin{array}{r}1 \cdot 79 \\
1 \cdot 50 \\
0.29 \\
0 \cdot 62 \\
0.88 \\
1.06 \\
1.06 \\
3.95 \\
84.0\end{array}$ & $\begin{array}{l}2 \cdot 1 \\
1 \cdot 73 \\
0 \cdot 37 \\
0 \cdot 56 \\
1 \cdot 17 \\
1 \cdot 19 \\
1 \cdot 19 \\
2 \cdot 14 \\
83 \cdot 0\end{array}$ \\
\hline
\end{tabular}

* Brain formalin fixed for two weeks.

$\dagger$ Results in g./100 g. fresh tissue.

found histologically. There is a considerable reduction in the quantities of the phospholipins and of cholesterol in the white matter. These results are compatible with those seen in the brain of a child of under 1 year of age, and would suggest an arrest of myelination at such an age, together with some degeneration of the myelin. The cortex shows far less change from the normal, but there is a very slight increase in cholesterol.

The most noticeable feature is the increased amount of cerebroside that is present in all areas in comparison with that found in a brain of a child of similar age. It is very difficult in children to obtain cortex free from the subcortical fibres, and this probably accounts for the relatively high figure found in the cortex, more especially as the amount of cerebroside found in the basal ganglia is much nearer the normal figure for the age.

Estimations of neuraminic acid were also made in view of the increase of cerebroside and of neuraminic acid in amaurotic family idiocy (Klenk and Langerbeins, 1941 ; Cumings, 1953), but the amounts of this substance were only just above the normal range in the white matter, the cerebral cortex and the basal ganglia in the brain of this case.

It would appear that the increase of cerebroside must be related to the presence of the stainable material in the globoid bodies. This would confirm by chemical methods the suggestion made by Hallervorden (1950) that this material might be kerasin, which is one of the cerebrosides in brain.

No organs from this case being available for examination, it was not possible to determine whether cerebroside was increased in areas other than the brain.

Comment.-This case is essentially similar, histologically, to those reported by Krabbe (1916), Neubürger (1922), Collier and Greenfield (1924), Eisner (1924), Ferraro (1927), de Lange (1940),
Einarson, Neel, and Strömgren (1944), Hallervorden (1950), Kaijser and Lundquist (1948), and de Lange (1950).

The case of Guillan, Bertrand, and Gruner (1941) was much more focal, the process being confined to the basal ganglia, pons, and medulla. Their case, like those of Ferraro, was in an adult. The spinal cord was involved in the only case in which all of it was examined (Kaijser and Lundquist, 1948).

Opinion has been sharply divided upon the origin of the globoid bodies or epithelioid cells as they have been called by many. Some authors have considered that they arose from astrocytes (Krabbe, Guillan, and others) either directly or in association with embryonic reversion such as is seen in gliomata (de Lange, Einarson, and others ; Kaijser and others). Collier and Greenfield considered them to be of astrocytic origin but Spielmeyer, to whom the sections were submitted, considered them to be of mesodermal origin, an opinion with which Greenfield (1950) now concurs. The mesodermal origin of the globoid bodies was first put forward by Neubürger who considered that they arose from vascular adventitial cells, an opinion with which Eisner and Hallervorden agreed. Ferraro (1944) considers that both adventitial cells and microglia may be involved. The earliest authors had not the advantage of the silver staining methods introduced by Del Rio-Hortega which, applied to the material from Case $\mathrm{C}$, appears to demonstrate quite clearly that the globoid bodies result from the attempt of phagocytes to deal with an abnormal P.A.S.positive material, which is cerebroside, and the histological appearances of these cells are compatible with a microglial origin.

\section{Summary}

Material from the brains of three cases of diffuse cerebral sclerosis has been examined, both histologically and chemically, but only one spinal cord was available for histological examination.

The brain and the spinal cord from an example of the "spongy type" (Canavan) showed similar histological features to those previously reported, while the chemical findings suggested an arrest of myelination of the cerebral white matter during late foetal life.

The second case, an example of the PelizaeusMerzbacher type, showed histological features typical of this disorder. Chemical analysis revealed a probable arrest of myelination of the white matter in early childhood, but with a more mature cortex which showed recent degeneration.

The last case, one of the Krabbe type, showed typical "globoid bodies" histologically. The 
material in these bodies was found chemically to be cerebroside and this substance had excited a microglial reaction.

We desire to express our thanks to those physicians already named, to Dr. T. N. Nauth-Misir and Dr. L. Phillips for the clinical details and post-mortem material of Case B, to G. T. M. Methold, Esq., H.M. Coroner for Guildford, for permission to publish the findings in Case C, and to Dr. E. K. Baasch for assistance with the foreign literature.

Our thanks are also due to Messrs. H. J. Cutmore, H. Goodwin, R. C. Shortman, and other members of the technical staffs for their assistance, and to Mr. J. A. Mills for the photographs.

The cost of the coloured plates was met by a grant from the Joint Research Advisory Committee.

\section{REFERENCES}

Bielschowsky, M., and Henneberg, R. (1928). J. Psychol. Neurol. Lpz., 36, 131 .

Bodechtel, G. (1929). Z. ges. Neurol. Psychiat., 121, 487.
Bogaert, L. van, and Bertrand, I. (1949). Acta neurol. psychiat. belg., 49, 572 .

Brain, W. R., and Greenfield, J. G. (1950). Brain, 73, 291.

Brante, G. (1949). Acta physiol. scand., 18, suppl. 63.

Canavan, M. M. (1931). Arch. Neurol. Psychiat., Chicago, 25, 299.

Collier, J., and Greenfield, J. G. (1924). Brain, 47, 489.

Cumings, J. N. (1953). 76, 551.

Einarson, L., Neel, A. V., and Strömgren, E. (1944). Actá Jutlandica, (Aarsskrift for Aarhus Universitet), 16, no. 1, p. 127. Aarhus and København.

Eisner, W. (1924). Virchows Arch. path. Anat., 248, 153.

Ferraro, A. (1927). J. nerv. ment. Dis., 66, 329, 479 and 616.

Ferraro, A. (1927). J. nerv. Ment. Dis., 66, 329, 479 and

Greenfield, J. G. (1933). Proc. roy. Scc. Med., 26, 690, and Volume Jubilaire en L'Honneur du Professeur G. Marinesco. Bucharest. (1950). Folia psychiat. Amst., 53, 255.

Guillain, G., Bertrand, I., and Gruner, J. (1941). Rev. neurol., Paris, 73, 401.

Hallervorden, J. (1950). Verh. dtsch. path. Ges., 32, 96.

Kaijser, K., and Lundquist, C. W. (1948). Nord. med., 39, 1355

Klenk, E., and Langerbeins, H. (1941). Hoppe-Seyl. Z. physiol. Chem., 270, 185 .

Krabbe, K. (1916). Brain, 39, 74.

Lange, C. de (1940). Ann. paediat., Basel, 154, 140.

- (1950). Folia psychiat., Amst., 53, 334.

Liebers, M. (1928). Z. ges. Neurol. Psychiat., 115, 487.

Löwenberg, K., and Hill, T. S. (1933). Arch. Neurol. Psychiat., Chicago, $29,1232$.

Merzbacher, L. (1910). Z. ges. Neurol. Psychiat., 3, 1.

Meyer, J. E. (1950). Arch. Psychiat. Nervenkr., 185, 35.

Neubürger, K. (1922). Z. ges. Neurol. Psychiat., 76, 384.

Norman, R. M. (1947). Brain, 70, 234.

Pelizaeus, F. (1885). Arch. Psychiat. Nervenkr., 16, 698. 